\title{
Collateral, Credit History, and the Financial Decelerator*
}

\author{
Ronel Elul ${ }^{\dagger}$
}

This Revision: March 2007

${ }^{*}$ I thank the editor and referees, seminar participants at the Atlanta FRB, Brown, European University Institute, Stanford (S.I.T.E.), Summer Camp in International Economics and Finance (Buenos Aires), Venice Workshop on Economic Theory, Technion, Wesleyan, and Yale University, and Mitchell Berlin, Piero Gottardi, and David N. Weil for many helpful comments. I am also grateful to the Hebrew University School of Business Administration for its hospitality.

${ }^{\dagger}$ Federal Reserve Bank of Philadelphia, Ten Independence Mall, Philadelphia, PA 19106-1574. E-mail: ronel.elul@phil.frb.org. The views expressed in this paper are those of the author and do not necessarily represent those of the Federal Reserve Bank of Philadelphia, or the Federal Reserve System. 


\begin{abstract}
We develop a simple model in which financial imperfections can serve to stabilize aggregate fluctuations, and not necessarily aggravate them as in much of the previous literature; we term this the financial decelerator. Stabilization can occur in our model because lenders are imperfectly informed as to borrowers' propensity to default; as a result it is too costly for lenders to impose borrowing constraints that guarantee repayment in every possible eventuality. This allows some borrowers to default when house prices are low, thereby leaving them with more wealth; this then serves as an endogenous stabilizing force.
\end{abstract}

Keywords: Financial accelerator, default, collateral, credit history JEL Classification Numbers: D52, E44, G12, G21, G33. 


\section{Introduction}

Much recent economic research develops the idea that financial factors can aggravate real fluctuations. The common theme of this work is that financial imperfections may introduce inefficiencies into financial markets that amplify economic downturns; a prominent example is Bernanke and Gertler (1989). In this work, it is typically the case that borrowing must be secured, because firms are unable to commit to repay their loans. A shock to the economy that lowers the value of some asset used as collateral then makes external financing more difficult to obtain; this, in turn, lowers economic activity and, hence, asset prices, even further. Similarly, in the context of housing markets, Stein (1995) constructs a model in which drops in housing prices mean that after paying off their mortgage, households have less money available to use as a down payment for a new house and so are less likely to be able to move, further depressing housing prices. ${ }^{1}$

The question we seek to answer in this paper is the extent to which this intuition is robust to the introduction of other, realistic financial imperfections, namely, adverse selection and strategic default. We find that, in fact, for a large set of parameter values these latter imperfections may actually serve as a stabilizing force.

In our model agents borrow to purchase housing and secure their loans with this long-lived asset. There are two financial imperfections in this model. First, in common with the previous literature, agents are unable to commit to repay their loans. This limits the amount that lenders are willing to offer. In addition, however, lenders are also imperfectly informed as to a borrower's propensity to default; that is, there is adverse selection. The latter imperfection implies that strategic default may actually occur in equilibrium.

\footnotetext{
${ }^{1}$ See also Ortalo-Magné and Rady (2006), who construct a life-cycle model of housing markets in which agents face credit constraints; in their model the magnitude of housing price fluctuations can exceed those of GDP.
} 
For relatively high house prices the commitment problem dominates, and the equilibrium is typically characterized by a standard financial accelerator; that is, the borrowing constraints that prevent default become tighter as falling prices reduce the wealth with which agents can collateralize future loans, thereby exacerbating aggregate fluctuations. However, we show that when prices are low, some agents will strategically default, which serves as a stabilizing force; we term this a financial decelerator.

The key reason for this is that under adverse selection what correspond to borrowing constraints in full-information models are actually endogenously determined in equilibrium. When house prices are high the equilibrium level of borrowing is sufficiently low that there is no default, and we obtain a financial accelerator as in the rest of the literature. When collateral values are low, however, agents will find it too costly to restrict their borrowing. There are then two possible outcomes. Either we will be in a separating equilibrium in which the bad types strategically default on their current loans, despite the cost this entails to their reputation; this will leave them with more income precisely in those states in which house prices are low. Alternatively, the equilibrium may continue to pool both types together, but will be characterized by more borrowing; this will make the bad types willing to repay now, but at the cost of allowing them to default in the future (because they have borrowed more). In either case current spending on housing will be higher, which will mitigate the decline in its price.

From this discussion one can see that a key feature of this story is the interaction between adverse selection and strategic default. Default is strategic in our model in the following sense. First of all, repayment is always an option in that agents do indeed have sufficient funds to cover their debts even when house prices fall. It is therefore important for our results that the defaulting agents be able to retain at least some of these funds when defaulting; this is discussed further in the next section. In addition, agents act strategically in weighing the costs and benefits of defaulting against those 
of repaying. Some of these costs are direct, in the form of the value of the collateral (house) that is surrendered upon default, as well as a personal cost of bankruptcy that each agent incurs; but they are also indirect, in the impact of default on a borrower's reputation.

We note that the type of strategic default we have in mind is seen by many to have played a role in the Texas housing crash of the mid-1980s. This is illustrated in the following statement by Judith Dedmon, head of Fannie Mae's Dallas office in 1987: "[i]n some neighborhoods, the homeowners would walk the house and go down the street and buy the same house at half the price" (The Dallas Morning News, March 18, 1996). The message of our paper is that strategic default can sometimes have the effect of stabilizing the housing market and that the impact on the economy might have been even more severe had borrowers been forced to repay all that they owed.

Although our approach is novel, we should point out that this is not the only paper to present a model that overturns the financial accelerator. Bacchetta and Caminal (2000) show that the agency costs facing creditconstrained firms can be aggravated by certain positive aggregate shocks (in particular a decline in the cost of funds), thereby allowing these agency costs to serve as a dampening force. And House (2006) shows that in models where financial imperfections lead to an over-investment problem, aggregate fluctuations that generate a decline in entrepreneurs' net worth may actually be more than offset by this over-investment. ${ }^{2}$

The plan of the paper is as follows. The following section presents the model. In section 3 we define and characterize equilibrium in our model. In section 4 we discuss the impact of aggregate fluctuations on house prices. We then give explicit conditions under which we obtain equilibria with financial decelerators and also discuss the empirical implications of our results.

\footnotetext{
${ }^{2}$ In addition, some have argued that the quantitative significance of financial constraints in terms of acceleration is rather small for reasonable choices of parameters; see Fuerst (1995) and Kocherlakota (2000).
} 
Section 5 presents examples that illustrate the general results of the paper. A detailed derivation of the equilibrium is given in the Appendix.

\section{The Model}

In this section we present our model. In section 3 we then explore the equilibrium of this economy, first focusing on the strategic interaction between agents when house prices are fixed and then on the determination of the market-clearing level of house prices.

\subsection{Agents and Contracts}

We work with a two-period model of the economy, in which the periods are denoted 1 and 2. There are two goods, a perishable numeraire and housing, the latter a long-lived asset from which agents accrue utility in each period they consume it. Since it is long-lived, housing is available for use as collateral on loans. The supply of housing will be fixed at 2 units.

The price of the perishable numeraire good will be normalized to $1 \mathrm{in} \mathrm{ev-}$

ery state. A key focus of this model is the interaction between housing price fluctuations and agents' behavior. To generate a source of price fluctuations in the cleanest manner possible we assume that there is a measure $1-\sigma$ of non-strategic agents who serve as an outside source of demand for housing. With equal probability, their spending on housing in period 1 will be either $\delta_{u}$ or $\delta_{d}$, which we will term the top and bottom nodes, respectively; these nodes correspond to the two aggregate states of nature. As a result, in period 1 the equilibrium housing price will have two possible values $-p_{1 u}$ and $p_{1 d}$ - corresponding to this exogenous demand. In order to make the analysis and interpretation of the model cleaner, we will restrict attention to parameter values that yield equilibria for which $p_{1 u}>1 \geq p_{1 d}>1 / 2$, so that there is only default in the bottom state. In period 2 they will spend 1 on housing, regardless of the state. As a result, all aggregate uncertainty 
will be resolved in period 1 . This will imply that there is a single period-2 value for the housing price corresponding to each node of period 1 - either $p_{2 u}$, if the current price is $p_{1 u}$, or $p_{2 d}$, if it is $p_{1 d}$.

There is also a competitive lending sector that is always willing to offer the numeraire on terms that provide it an expected return of $1 .^{3}$ This is discussed further below.

We also make the following assumptions regarding lending contracts, which we discuss in detail in the following section. First, we restrict attention to debt contracts in which the interest rate $r$ is fixed and cannot be indexed (for instance, to house prices). In addition, we assume that there are no deficiency judgments - that is, should a borrower refuse to pay, the lender does not have recourse to any assets other than the housing purchased with the proceeds of this loan, nor to the borrower's future income.

We will primarily be interested in the consumers of housing, whom we will also refer to as "strategic agents." We assume that they have measure $\sigma$ and that they share the following characteristics:

- Each strategic agent enters period 1 with two units of housing.

- We also assume that they have financed the purchase of this housing by borrowing two units of the numeraire (as in Stein, 1995), and that they have used the housing to secure this debt (although for low values of the house price it may not suffice to cover the entire loan).

\footnotetext{
${ }^{3}$ We thus assume that the losses incurred by lenders when consumers default do not impact their ability to lend further. Although this is a restrictive feature of our model, we have in mind more generally that the negative impact of these losses is smaller than the positive effect of the additional funds available to the strategic defaulters. This is in fact a natural outcome of most models in which agents have a choice between consumption and lending - those with the lower marginal propensity to consume out of current income will naturally emerge as the lenders (see Tobin, 1975). Likewise, we do not model the possibility that capital requirements could constrain banks in such a manner that an increase in default would leave them with fewer funds to lend; while such an effect would again mitigate our financial decelerator, it would likely not eliminate it completely. Finally, although we assume here that the supply of funds is perfectly elastic so long as lenders break-even in expectation, our results would be qualitatively similar were we to generalize this.
} 
The timing of repayment and consumption is as follows. At the start of period 1 the exogenous shock to housing demand is realized, which determines whether we are in the top or the bottom node. A strategic agent first makes a repayment on his initial loan of 2 ; this repayment may be partial (for example, if he defaults and surenders his collateral). He then has an opportunity to borrow further; the rate lenders charge him depends on whether or not he repaid his loan in full. Finally, he is able to consume from his wealth, which is the sum of whatever he retains after repaying his loan and his borrowing. In period 2 , there is no further realization of uncertainty. The agent first makes a repayment and then consumes; there is no further borrowing. This timing is illustrated in Fig. 1.

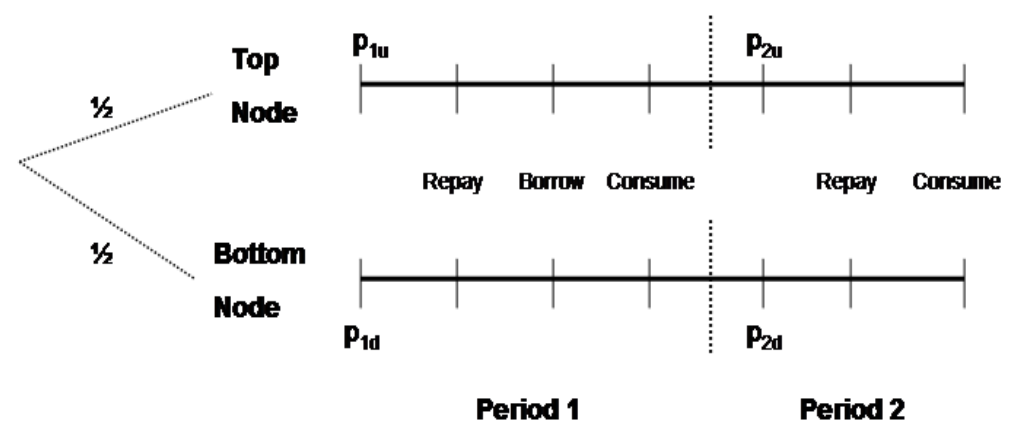

Figure 1: Timing of the Model 


\subsection{Consumers}

The strategic consumers consume only housing in period 1 , and both housing and the numeraire in period $2 .{ }^{4}$ Conditional on the realization of uncertainty in period 1, an agent consuming $\left(h_{1 j}, h_{2 j}\right)$ units of housing and $x_{2 j}$ units of the consumption good (in period 2) accrues the following utility: $v\left(h_{j}, x_{j}\right)=$ $\log \left[h_{1 j}\right]+\left(x_{2 j}+\log \left[h_{2 j}\right]\right)$, where $j \in\{u, d\}$.

These agents will have income $i_{1} \equiv i=1 / 2$ in either node of period 1 (this is high enough so that default is truly strategic for the parameters we consider). Since they have quasi-linear utility, it will also be the case that if we assume that their income in period 2 is sufficiently high, then their period-2 housing consumption will be income-inelastic (in particular, $i_{2}>2$ suffices). Given this assumption, we will see that the equilibrium price is $p_{2}=1 / 2$ in either node of period 2 .

In addition, strategic agents also have a fixed personal cost of default, denoted by $\kappa \in[0,1]$, which is deducted from their utility in any period in which they default. So for example, conditional on being in the bottom node, an agent with cost $\kappa$ who defaults in period 2 (but not period 1) would obtain utility $v\left(h_{d}, x_{d}\right)-\kappa$. If he defaulted in both periods of the bottom node, he would accrue $v\left(h_{d}, x_{d}\right)-2 \kappa$.

The agents are distinguished by this cost of default. We will assume that a fraction $1-\beta$ of the consumers are "good" in that they have a high cost of default $\kappa=1$, while the other $\beta$ are "bad" and have a lower cost $\kappa=k$, with $k \in(0,1 / 2]$; later we will characterize the equilibrium as we vary $\beta$ and $k$. By choosing the default cost of the good agents to be $\kappa=1$ we ensure that there will always be an equilibrium in which they do not default; this allows us to focus on the strategic interaction between reputation and default.

We also assume that this default cost is private information - lenders do not observe it directly, although borrowers' behavior can be used to make

\footnotetext{
${ }^{4}$ By restricting consumption to housing in period 1, we do not need to distinguish between secured and unsecured loans, thereby simplifying the model.
} 
inferences about it. This is in line with actual practice in credit markets; credit bureaus devote considerable resources to using borrower behavior to infer information about their likelihood of defaulting in the future.

In employing default costs, we follow Dubey, Geanakoplos, and Shubik (2005), although we take these costs as fixed, rather than as increasing in the magnitude of default. These costs can be interpreted as a household's "social stigma" from a bankruptcy filing or else as summarizing the cost associated with bankruptcy, such as lawyers' fees and time wasted in court. Since we do not want to arbitrarily exclude defaulters from credit markets (in contrast to Kehoe and Levine, 1993 and many others), we must discourage default through these costs. In addition, since it is natural to interpret at least some of these costs as being private information, this gives us a way to introduce adverse selection into our model.

\subsection{Discussion}

In this section we discuss the assumptions we have made regarding the types of contracts into which market participants can enter. Recall that we assumed that the only contracts available are debt contracts that are not indexed to house prices and which preclude deficiency judgments. In broad terms, there are several salient generalizations of such a contract: multiple periods, allowing lenders to seize agents' non-housing wealth, and payments that are indexed to house prices.

First of all, one might consider contracts with payments that span several periods. We do not consider such an extension, since the fact that we have assumed that agents begin our model with a fixed inherited debt would put this beyond the scope of our model. Furthermore, endogenizing the initial borrowing (which would be needed to consider the effect of multiperiod contracts) would result in a much more complicated model for which it would be difficult to obtain analytic results.

In the context of our model, however, the most significant assumption 
we make is that deficiency judgments are prohibited. In particular, if a homeowner defaults on his mortgage, then lenders cannot seize his other (non-housing) assets, nor can they attach any future income or assets. This is significant because the ability by homeowners to strategically default is a key driver of our stabilizing mechanism. We will argue first of all that this restriction accords with actual market practice. In addition, we will briefly discuss why such restrictions might be optimal when viewed from a broader perspective.

First, this restriction accords with actual market practice. Deficiency judgments are essentially prohibited in nine U.S. states, which together account for over one-third of all mortgage lending (see Pence, 2006, for details.) In addition, the Federal Housing Administration has a policy of not pursuing deficiency judgments on loans that it guarantees (making up approximately 10 percent of all mortgages). ${ }^{5}$ Furthermore, as Capone et al. (1996) point out, deficiency judgments are rarely carried out even when they are permitted because the borrower can often protect his remaining assets, as well as his future income, through a bankruptcy filing. In particular, a deficiency judgment is considered an unsecured debt which can be discharged through a bankruptcy filing. So if the borrower lives in a state with generous personal property exemptions, he may well be able to protect sufficient assets to allow him to purchase a new home. Consistent with this, empirical work has found that laws allowing deficiency judgments have no effect on lender losses (Clauretie and Herzog, 1990).

More generally, the restriction on deficiency judgments, and the ability by borrowers to discharge deficiencies through a bankruptcy filing, may be viewed as one part of a broader "fresh start" policy. While such restrictions

\footnotetext{
${ }^{5}$ Deficiency judgments are also prohibited in some European countries (Austria, Italy, and the Netherlands); however, even in those countries where the lender is permitted to collect the outstanding balance, there is typically a time limit on the duration of the homeowner's liability (for example, in the UK it is 6 years). For further details, see European Mortgage Federation (2002).
} 
on free contracting may appear to be suboptimal from a narrow perspective, they may be the outcome of a political economy model (Bolton and Rosenthal, 2002), or they may result from concerns that free contracting could leave agents underinsured (Aghion and Hermalin, 1990.)

The other assumption we make is that the debt payments in our model (in particular the payment due in period 1) are fixed in nominal terms and cannot be indexed to house prices. This might be important for two related reasons. First, were agents contractually permitted to pay less when house prices fell, the incentive to default would be reduced. Additionally, by allowing lenders to offer indexed contracts, they might be able to separate the two types more easily. Notwithstanding, note that our assumption is consistent with actual practice. Aside from the general reasons why we do not observe inflation-indexed contracts (see Fisher, 1983, for example) there are additional factors that explain why in practice contracts are not indexed to house prices in particular. The most important of these is that the majority of movements in individual house prices are due to idiosyncratic factors, rather than resulting from aggregate volatility that could be captured by an index. For example, while the average house price volatility is 10 percent per year, the OFHEO house price index has a volatility of only 2 percent. This would obviously make tying payments to an individual house price difficult. ${ }^{6}$

\subsection{Consumer Optimization}

We now discuss how strategic consumers optimize in this model.

Consumers take prices for housing as given, as well as interest rates on their borrowing. They then optimize with respect to these prices and rates.

Recall that the prices are $p_{1 u}$ in the top node of period 1 and $p_{1 d}$ in the bottom node, and $p_{2 u}$ and $p_{2 d}$ in period 2. The interest rate for the initial

\footnotetext{
${ }^{6}$ One exception that proves the rule is Stanford University's Mortgage Assistance Program, which is of course highly restricted in scope - both to properties in a very small geographic area as well as to a narrow class of borrowers (those who are employed by the university).
} 
loan, which the agents must repay at the beginning of period 1 (regardless of the state of nature), will be given by $r_{0}$. For simplicity we will restrict attention to parameter values such that there is only default in the bottom nodes (i.e., when the house price goes down). In particular, we will have $p_{1 u}>r_{0}$ in equilibrium. As a result, we will focus attention primarily on the bottom node because that is where default occurs (since $p_{1 d}<r_{0}$ ); we briefly discuss the top node of the game in appendix B.

The second period interest rates are $r_{u}$ and $r_{d}$, for the top and bottom nodes respectively. Since default can occur in the bottom node of period 1, lenders will also be able to condition the rate $r_{d}$ on an agent's repayment behavior in period 1 .

Given these prices and interest rates, agents' decisions are then: ${ }^{7}$

- Whether to default on their original loan in a given node of period 1

- Given their default decision, how much to borrow

- Whether or not to repay in the final period (depending on the node and on how much they borrowed in the previous period)

Note that since lenders observe only whether or not an agent defaults, and the default penalty is incurred if and only if an agent does not repay the full amount owed, it will be optimal for borrowers to either repay the minimum possible (i.e., the collateral value) or else the full amount owed.

\footnotetext{
${ }^{7}$ In addition, agents must also allocate their wealth between housing and the numeraire, but this is straightforward. Recall that the strategic agents consume only housing in period 1. In period 2 , since they have quasi-linear utility, with $i_{2}>2$, and since we will have $p_{2 j}=1 / 2$, the agents will consume two units of housing and apply their remaining wealth to purchasing the numeraire.
} 


\section{Equilibrium}

\subsection{The Equilibrium Concept}

In this section we discuss the equilibrium in our model. The equilibrium concept we use will need to account both for the strategic interaction between agents, as well as market-clearing in the housing market.

In particular, we define the equilibrium in this model as follows.

In each period, consumption is determined as the equilibrium outcome of a "lending game" between borrowers and lenders, where agents take house prices as given. In this game lenders offer contracts (borrowing amounts and associated interest rates); in period 1 these offers can also be conditioned on a borrower's repayment behavior, since this is public knowledge. Because of Bertrand competition, we also assume that rates must be set so that lenders break even in every period.

Finally, we require that house prices be such that housing markets clear, where consumption is given by the outcome of the lending game, as described above.

Since this is a model of adverse selection in which pooling and separation play a major role, we choose to work with the Wilson-Miyazaki equilibrium of the lending game, as in Miyazaki (1977) and Wilson (1977). A set of contracts will be a Wilson-Miyazaki equilibrium if no contract earns negative profits for lenders (indeed, because of perfect competition they will actually break even) and if there is no set of contracts that could be profitably introduced if all contracts that earn negative profits in its presence were withdrawn.

This is an appealing solution concept in the context of our model, because unlike the Nash equilibrium, it allows for pooling equilibria. This then means that strategic default can occur, because lenders will not ration the bad types so much that they do not default. By contrast, no pooling contract can be a Nash equilibrium, as in Rothschild and Stiglitz (1976). 
The reason is that lenders would always have an incentive to offer a slightly safer contract in order to "cream-skim" the best types; the only contracts that would be immune to this would be ones that involve so little borrowing that they are riskless. Note by contrast that such cream-skimming would not be profitable if the original contract can be withdrawn, which is why the Wilson-Miyazaki equilibrium admits pooling. ${ }^{8}$

\subsection{Equilibrium of the Lending Game}

\subsubsection{Borrowing Constraints}

Given that agents are free to default, lenders of course impose borrowing constraints. These constraints must be derived before we can characterize the equilibrium.

Since lenders must at least break even in each period, they cannot offer more than the best agent in a given pool would repay. For example, while it may be the case that the "bad" agents default in a pooling equilibrium, the good agents must repay, since otherwise lenders would not be able to break even. As discussed earlier, this constraint is weaker than that which is assumed in classic financial accelerator models; those models typically rule out any strategic default whatsoever in equilibrium.

In the initial period (period 0 ), since the debt is fixed at 2 units, and agents' income in the following period is $i_{1}=1 / 2$, this constraint leads rather to a restriction on parameter values so as to ensure that the good agents are able to repay in the low state. That is, in order for the lenders to break even, we restrict attention to parameters that imply that in equilibrium we always have $2\left(r_{0}-p_{1 d}\right) \leq i_{1}=1 / 2$, with $r_{0}$ given below.

The constraints are more complicated in period 1. In general, for an agent whose default cost is known by lenders to be $\kappa$ and with period-1

\footnotetext{
${ }^{8}$ Nevertheless, many of our results would still carry through were we to use Nash equilibrium, because stabilization also obtains through default in period 1 (which could still occur since the initial loan is specified exogenously).
} 
wealth $i$, the maximal borrowing $b_{\max }$ that is consistent with this agent repaying in the following period satisfies:

$$
\left[i+b_{\max }\right] \frac{p_{2}}{p_{1}}-b_{\max }=-\kappa
$$

where $p_{1}$ is the house price in period 1 in this node and $p_{2}$ its price in the following period of the same node. The left-hand side is derived by noting that his spending on housing in period 1 will be $i+b_{\max }$, and so the value of his collateral in period 2 will be $\left(i+b_{\max }\right) \frac{p_{2}}{p_{1}}$; against this he owes $b_{\max }$ from his period-1 borrowing (the gross interest rate will be $r_{d}=1$ because the constraint ensures that he will repay). The right-hand side is simply the disutility of defaulting in period 2.

We now focus attention on the bottom node (the top node is discussed in the appendix). Since an agent who defaults is known to be the bad type (good types do not default in equilibrium), Eq. (1) will give the borrowing constraint for these agents. Recall that the bad types have default cost $\kappa=k$; since default will allow these agents to retain all of their income of $i_{1}=1 / 2$ (and surrender only their collateral), their borrowing constraint will be determined by substituting these values into (1), which can then be solved to yield

$$
b_{\max }^{\mathrm{def}}=\frac{4 k p_{1 d}+1}{4 p_{1 d}-2}
$$

For the pool of agents who do not default in equilibrium, the derivation of the borrowing constraint is slightly more complicated. First of all, note that there can be both good and bad types in this pool; since the bad types may yet default in period 2 , the interest rate that must be paid in period $2, r_{d}$, is not necessarily equal to 1 . In addition, since the agents will have repaid in period 1 , their wealth in this period is actually $1 / 2+2\left(p_{1 d}-r_{0}\right)$. Finally, note that it is now the best agents in the pool (the ones with default $\operatorname{cost} \kappa=1$ ) to whom lenders refer in determining the borrowing constraint. As a result, the maximal borrowing is given as the solution $b_{\max }^{\text {nodef }}$ to the 
following equation:

$$
\left[1 / 2+2\left(p_{1 d}-r_{0}\right)+b_{\max }^{\text {nodef }}\right] \frac{p_{2 d}}{p_{1 d}}-b_{\max }^{\text {nodef }} r_{d}=-1 .
$$

Since we will show below that this constraint never binds in equilibrium, we do not report the solution to this equation.

\subsubsection{Candidate Equilibrium Allocations}

We now discuss the equilibrium allocations in the bottom node. We will show that - depending on the parameter values and the equilibrium housing price - the equilibrium of the lending game falls into one of three possible "regimes," which we term "safe," "risky," and "default." We will provide a summary of the equilibrium in this section; the detailed derivations can be found in appendix A.

The three regimes are as follows:

- Safe: All agents repay in period 1 and then borrow the maximal amount that is consistent with no default in period 2 .

- Risky: All agents repay in period 1, but then borrow more than the safe level, so that the the bad types default in period 2 .

- Default: The bad types default in period 1 and then borrow the maximum possible ( $b_{\max }^{\mathrm{def}}$, as derived in (2) above). The good types repay and borrow just enough so that the bad types are indifferent to defaulting.

The first two types of equilibria are both pooling, in which all agents choose to repay in the first node of the bottom period and then borrow the same amount. There are two possible types of pooling equilibria.

One possibility is that the second-period borrowing is sufficiently low that all types repay in period 2 and there is no default; this is the safe regime. In particular, note that after repaying borrowers are left with wealth 
$1 / 2+2\left(p_{1 d}-1\right)$. If the bad types have a default cost of $k$, then the maximal borrowing that is consistent with their repaying is

$$
b_{\text {safe }}=\frac{4(1+k) p_{1 d}-3}{4 p_{1 d}-2},
$$

which is the solution to

$$
\left[1 / 2+2\left(p_{1 d}-1\right)+b_{\text {safe }}\right] \frac{p_{2 d}}{p_{1 d}}-b_{\text {safe }}=-k .
$$

Alternatively, both types can repay in period 1, but the equilibrium level of borrowing can be higher, so that the bad types default in period 2; this is the risky regime. The resulting borrowing in this case will be given by $b_{\text {risky }}=\frac{14 p_{1 d}-3-4 \beta p_{1 d}-8 p_{1 d}^{2}}{4 p_{1 d}-2}$, which is greater than $b_{\text {safe }}$. This is the level that maximizes the good types' utility when the types are pooled and the bad types default in period 1; for further details see Eqs. (A-3) and (A-4) in appendix $\mathrm{A}$.

Finally, the equilibrium can be separating, with the bad types defaulting in period 1 and the good types repaying. We call this the default regime. In this case the bad types will borrow the maximum possible, which is given by their borrowing constraint $b_{\max }^{\mathrm{def}}$, as derived in Eq. (2) above. The equilibrium borrowing for the good types will be the maximum consistent with separation - that is, the maximum that leaves the bad types willing to default. We denote this by $b_{\text {def }} \equiv \frac{6+\beta-8 p_{1 d}}{4-2 \beta}+\frac{(1+2 k) p_{1 d}}{e^{k}\left(2 p_{1 d}-1\right)}$, which is derived in Eq. (A-8) of appendix A.

For given parameter values and house prices, the Wilson-Miyazaki equilibrium will be characterized by a unique choice of regime. The particular regime that obtains will be the one that is stable against deviations by both borrowers and lenders. This must be determined by numerical simulation using the expressions for the agents' utilities associated with each regime; these are derived in appendix A. Using the results in the appendix, we sim- 
ulate the equilibrium for a variety of parameter values ${ }^{9}$ and summarize the results in Fig. 2, which is discussed below. In addition, we can also describe some qualitative features of the equilibrium.

For example, for low house prices the safe regime cannot be an equilibrium because the bad types would want to default and borrow $b_{\max }^{\text {def }}$ in preference to repaying and borrowing $b_{\text {safe }}$. Conversely, the default regime can only be an equilibrium when house prices are sufficiently low.

Finally, the risky regime exists only when $\beta$ and $k$ are sufficiently low; in particular, we show in the appendix (see Eq. (A-5)) that a necessary condition for the risky regime to exist is that $\beta+\frac{1+2 k}{2 e^{k}} \leq 1$. The reason is that when $\beta$ is high, i.e., when there are many bad types, the good types find the bad types' period-2 default too costly, and a lender can cream-skim them by offering a more attractive contract in which they borrow less - either one in which the bad types do not default (i.e., they can deviate to the safe regime) or else one that separates the bad from the good (a deviation to the default regime). Similarly, when $k$ is high the bad types may deviate from the equilibrium by defaulting and then borrowing $b_{\max }^{\text {def }}$; this will be profitable because they can borrow relatively more on their own when $k$ is high.

In Fig. 2 we report the equilibrium regimes that obtain as we vary the house price for a given pair of parameter values $(\beta, k)$. For example, as discussed above, for $\beta+\frac{1+2 k}{2 e^{k}}>1$, the risky equilibrium does not exist; as we go from high house prices ( $p_{1 d}$ close to 1 ) to low ones we move from the safe equilibrium to the default equilibrium. This is referred to in the Figure as "S-D." Conversely, for very low values of $\beta$ and $k$, the equilibrium will be risky for any price $p_{1 d}$; this is denoted as " $\mathrm{R}$ " in the Figure. Last, for intermediate values of $\beta$ and $k$ all regimes can exist; for high house prices we are in the safe regime, for intermediate ones in the risky regime, and for low ones we are in the default regime; this is denoted "S-R-D."

\footnotetext{
${ }^{9}$ We use a $50 \times 50$ grid, with $\beta \in[0,1]$ and $k \in[0,0.5]$.
} 


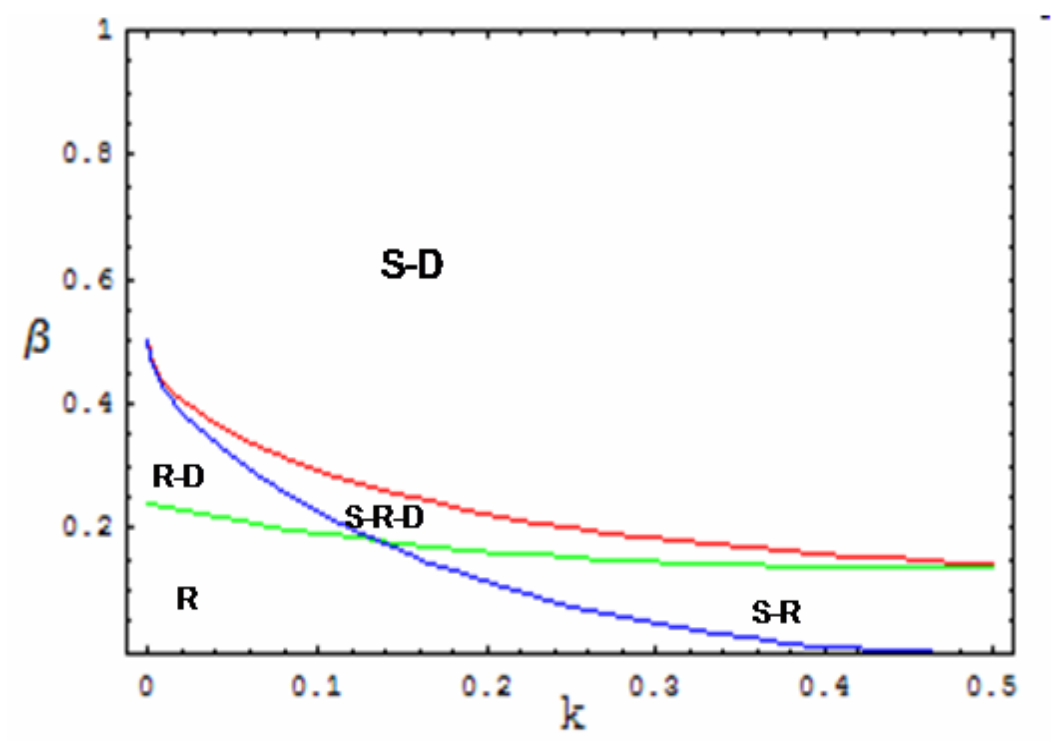

Figure 2: The equilibrium regimes obtained as $p_{1 d}$ varies, for selected values of the bad types' default cost $k$ and the measure of bad types $\beta$.

\subsection{General Equilibrium}

We now discuss the determination of the market-clearing house prices, given that agents play a Wilson-Miyazaki equilibrium of the lending game as described in the previous section. Recall that lenders set interest rates so that they earn an expected return of 1 for each unit lent. Thus only the housing prices $p_{1 d}, p_{1 u}, p_{2 d}, p_{2 u}$ need to be determined by market-clearing, given the strategic agents' demand for housing implied by the Wilson-Miyazaki equilibrium of the lending game. We first give the market-clearing conditions that determine these prices. We then give conditions under which we obtain a financial decelerator in equilibrium.

Recall that the supply of housing in the second period is 2 units, and that the non-strategic agents' spending on housing is 1 (regardless of the state). Since utility is quasi-linear in the second period and the strategic consumers are assumed to have sufficient funds in period $2\left(i_{2}>2\right)$, the 
second-period market-clearing house prices will thus be $p_{2 u}=1 / 2=p_{2 d}$, regardless of the state.

In period 1, recall that that the measure of strategic consumers is $\sigma$ (and $1-\sigma$ for the non-strategic) and that the outside (non-strategic) spending on housing is $\delta_{d}$ and $\delta_{u}$ in the bottom and top nodes, respectively. We will focus attention on the bottom node; the top node is discussed in appendix B.

In the safe regime, the strategic agents spend

$$
1 / 2+2\left(p_{1 d}-1\right)+b_{\text {safe }}=p_{1 d}\left(2-\frac{1-2 k}{2 p_{1 d}-1}\right)
$$

on housing (see appendix A for further details). So the price in the bottom node is determined by the following market-clearing condition:

$$
\sigma\left(2-\frac{1-2 k}{2 p_{1 d}-1}\right)+(1-\sigma) \frac{\delta_{d}}{p_{1 d}}=2 .
$$

In order to guarantee that equilibrium always exists in this model, we impose assumptions that ensure that the law of demand holds - that is, as the outside housing demand falls, the equilibrium price falls as well (otherwise, as we reduce the outside demand $\delta_{d}$ there may be no price that clears the market). In order for this to be the case, however, we cannot have too many strategic consumers, since in the safe regime their borrowing constraints lead to a financial accelerator in which falling prices actually decrease their demand. By examining the market-clearing condition in (6) above, we can deduce that for the parameter values we consider below, it is sufficient for strategic agents to make up less than two-thirds of the population, i.e.,

Assumption 1: $\sigma<2 / 3$.

For the risky regime, spending by the strategic agents is similarly

$$
1 / 2+2\left(p_{1 d}-1\right)+b_{\text {risky }}=p_{1 d}\left(\frac{2(1-\beta)}{2 p_{1 d}-1}\right)
$$


and so the market-clearing condition is that

$$
\sigma\left(\frac{2(1-\beta)}{2 p_{1 d}-1}\right)+(1-\sigma) \frac{\delta_{d}}{p_{1 d}}=2
$$

Finally, in the default regime the bad types default, leaving them with income $1 / 2$ after defaulting, and borrow a further $b_{\mathrm{def}}^{\mathrm{max}}$, while the good types repay (leaving them with income $1 / 2+2\left(p_{1 d}-r_{0}\right)$ ) and borrow $b_{\text {def }}$. Since a fraction $\beta$ of the strategic types are bad, the total per capita strategic spending on housing is

$$
\beta\left(1 / 2+b_{\mathrm{def}}^{\max }\right)+(1-\beta)\left[1 / 2+2\left(p_{1 d}-r_{0}\right)+b_{\mathrm{def}}\right]=p_{1 d}\left(\frac{1+2 k}{e^{k}\left(2 p_{1 d}-1\right)}\right)
$$

Thus to clear the housing market we must have

$$
\sigma\left(\frac{1+2 k}{e^{k}\left(2 p_{1 d}-1\right)}\right)+(1-\sigma) \frac{\delta_{d}}{p_{1 d}}=2
$$

\section{The Financial Decelerator}

In this section we discuss the implications of financial imperfections for the impact of aggregate fluctuations on house prices. We begin by defining the financial accelerator and decelerator, then we link them to the various classes of equilibria presented in the previous sections. We also give conditions under which strategic default will play a stabilizing role and discuss the empirical implications of our model.

\subsection{Accelerators and Decelerators}

The various regimes that we described have very different implications for the impact of aggregate fluctuations on house prices. Before we explore this further, we must characterize our benchmark - an unconstrained economy with no imperfections. The strategic agents' demand for housing in such an 
economy coincides with that in the risky equilibrium when there are no bad types (i.e., $\beta=0$ ), namely, $\frac{2}{2 p_{1 d}-1}$ as per (7) above. ${ }^{10}$

Having specified our benchmark, we can now define the financial accelerator and decelerator.

Definition: An economy will be characterized by a financial accelerator in some region if a (small) drop in the non-strategic spending for housing in the bottom node of period 1 leads to a larger decline in the equilibrium housing price than in the unconstrained economy. Conversely, if it leads to a smaller decline in the equilibrium housing price, then we will say that the economy is characterized by a financial decelerator in this region.

We can now trace out the implications of the different regimes for the response of equilibrium house prices to changes in the exogenous demand.

When we are in the safe regime, demand for housing by the strategic consumers is $2-\frac{1-2 k}{2 p_{1 d}-1}$. Observe that as $p_{1 d}$ decreases, housing consumption also goes down; for the parameters we consider in the paper, this is also the case for spending on housing. The reason housing demand goes down is that in the safe regime borrowing is determined by the no-default constraint of the bad types, which gets tighter as the house price falls, because the agents' collateralizable wealth declines. This is an instance of the classic "debt deflation" (Fisher, 1933) and it means that the safe equilibrium will be characterized by a financial accelerator, for precisely the same reasons as in the rest of the literature.

In the other two regimes, however, the borrowing constraint no longer completely eliminates default. We show, moreover, that strategic default has the effect of stabilizing the economy in these two regimes by precluding debt deflation; as a result these regimes are not characterized by a financial accelerator.

In the risky regime, Eq. (7) tells us that the strategic consumers' housing demand is $\frac{2(1-\beta)}{2 p_{1 d}-1}$, where now $\beta>0$. This demand is lower than the

\footnotetext{
${ }^{10}$ Since the good types' borrowing constraint does not bind in the risky equilibrium.
} 
unconstrained spending (by a factor $1-\beta$ ); this reflects the good types' response to free-riding by the bad types. Observe, however, that demand no longer depends on the agents' collateralizable wealth, and thus there is no financial accelerator within this regime; in this sense the economy behaves as if it were unconstrained. The reason is that now the bad types strategically default in period 2 equilibrium; this then implies that their collateral constraint - which led to debt deflation in the safe regime - no longer binds.

Finally, in the default regime, strategic agents' housing consumption is given by $\frac{1+2 k}{e^{k}\left(2 p_{1 d}-1\right)}$; this is the weighted average of consumption by the good and bad types as derived in Eq. (9). As in the risky regime, while adverse selection reduces consumption relative to the first best (now, since $k<1$ ), the fact that the bad types strategically default (now, in period 1) again implies that we have no accelerator and the economy responds to shocks as if it were unconstrained.

In addition, we will now show that in the transition across regimes, strategic default can sometimes have a decelerating effect. That is, the response of the economy to shocks that drive us across regimes will be weaker than in an unconstrained economy.

First recall that as prices fall we go from the safe, to the risky, and finally the default regime (although not all of these will necessarily occur for all parameter values).

When the parameter values are such that the risky equilibrium never exists, then the transition - from the safe to the default regime - is continuous. ${ }^{11}$ The fact that we move from a (safe) equilibrium with a financial accelerator to an equilibrium (the default regime) without one means that

\footnotetext{
${ }^{11}$ To see this, first note that the equilibrium switches from the safe to the default regime when $p=p_{\text {nodef }}$, as derived in Eq. (A-2). Substituting this price into the expressions for housing demand in each regime ((5) and (9)) demonstrates that demand in each regime is identical at this price and so the market-clearing price will be continuous across the regimes.
} 
the response of the price and the strategic agents' demand to changes in the outside demand $\delta_{d}$ across this transition will be muted as compared to the safe regime, but this response will still exceed that of the unconstrained benchmark (or, equivalently, the response inside the default regime itself). This may be seen in Fig. 3 below, for example.

In general, however, the risky regime will also exist. By comparing the demand in the safe and risky regimes ((5) and (7), respectively), we can conclude that housing demand in the risky regime is always higher when it exists. $^{12}$ As a result, the transition from the safe to the risky regime will in fact be characterized by a financial decelerator. More precisely, the fact that demand in the risky regime is higher than that in the safe means that in order to ensure that equilibrium exists as we move across these regimes we must randomize, ${ }^{13}$ so in fact housing consumption (and prices) will be completely inelastic with respect to changes in the outside demand $\delta_{d}$ during this transition (see Fig. 4, for example).

Finally, when the house price (or, equivalently, the outside demand) is sufficiently low, we switch from the risky to the default regime. By comparing (7) and (9) we can see that consumption in the default regime can only exceed that in the risky regime if $\beta>1-\frac{1+2 k}{2 e^{k}}$. But as discussed earlier this implies that the risky regime does not exist, ${ }^{14}$ a case we covered earlier and hence rule out here. So going from the risky to the default regime must entail a drop in aggregate housing demand (and so an accelerator relative

\footnotetext{
${ }^{12}$ This is implied by condition (A-6) below.

${ }^{13}$ In particular, we assume that a fraction $\gamma \in(0,1)$ of the agents are randomly assigned to play the risky equilibrium, and a fraction $1-\gamma$ play the safe. Here $\gamma$ is chosen to keep the market price fixed given the outside demand; at this price the good types are indifferent between the safe and risky equilibria. In addition, we give lenders the off-equilibrium-path belief that if an agent deviates, he is assumed to be the bad type. Of course, the bad types all prefer the risky allocation (since this allows them to borrow more without repaying in the final period), but since deviating would signal their type to lenders (since the good types are indifferent), they do not switch. As $\delta_{d}$ falls, the fraction $\gamma$ of agents assigned to the risky regime of course increases, until it reaches 1 , at which point we are in a pure risky regime (and henceforth the price falls as $\delta_{d}$ drops).

${ }^{14}$ See Eq. (A-5) for the detailed derivation.
} 
to the unconstrained case).

Summary: In our model we can have (i) a "standard" accelerator in the safe regime, (ii) an economy that responds as if it were unconstrained in the risky and default regimes, and (iii) deceleration or acceleration as the equilibrium transitions from one regime to another.

\subsection{The Financial Decelerator in Equilibrium}

By building on the discussion above, we can give the following results, which establish conditions under which our original intuition holds - that is, when prices are high we obtain an equilibrium with a financial accelerators, whereas when they are low strategic default stabilizes the economy.

The simplest condition is one that rules out the risky regime (so that prices do not drop when we switch to the default regime); as discussed above we know that $1-\frac{1+2 k}{2 e^{k}}<\beta$ suffices (see Eq. (A-5)).

So that our equilibrium exists, we also restrict the variation in outside demand $\delta_{d}$, which simply ensures that (i) in the bottom node the equilibrium housing price $p_{1 d}$ is no greater than 1 , and (ii) that $i_{1}+2 p_{1 d} \geq 2 r_{0}$, so that default is truly strategic - that is, agents are always able to repay should they choose to. ${ }^{15}$

Assumption 2: $\delta_{d} \in\left[\frac{e^{-k}(6+\beta)\left(e^{k}(2+\beta)-2 \sigma(1+2 k)\right.}{4(2+\beta)(1-\sigma)}, \frac{2-\sigma-2 k \sigma}{1-\sigma}\right]$

This then allows us to formulate the following Proposition.

Proposition 1: Given Assumptions 1 and 2, when $1-\frac{1+2 k}{2 e^{k}}<\beta$ then there exists an equilibrium of this economy in which housing markets clear and agents play a Wilson-Miyazaki equilibrium of the lending game. For $\delta_{d}$ sufficiently high the equilibrium is characterized by the safe regime and for $\delta_{d}$ sufficiently low the default regime prevails. Moreover, the safe regime is characterized by a financial accelerator, and in the default regime strategic

\footnotetext{
${ }^{15}$ This is derived from Eqs. (6)-(10).
} 
default stabilizes the economy so that it responds to shocks as if it were unconstrained.

It is also not difficult to give conditions that rule out a financial accelerator altogether; this requires finding parameters for which only the risky regime can occur in equilibrium. From the expressions for the good types' utility in each regime (see (A-9)-(A-11)), this occurs when $\beta$ and $k$ are sufficiently close to 0 , as can also be verified from Fig. 2. Intuitively, the reason is that with low $\beta$ the free-riding problem is not severe in the risky regime, so that it is immune to deviations by either type. Similarly, with low $k$ the borrowing in the safe and default regimes is low, again making the risky regime more attractive.

As above, we also impose restrictions on the outside demand that keep $p_{1 d}$ below 1 and also ensure that it is sufficiently high that default is a strategic decision $\left(p_{1 d}>3 / 4\right.$ suffices in this regime). From the marketclearing condition (8), we can see that the necessary assumption is as follows: Assumption 3: $\delta_{d} \in\left[\frac{3(1-2 \sigma(1-\beta)}{2(1-\sigma)}, \frac{2(1-\sigma(1-\beta)}{(1-\sigma)}\right]$.

The following Proposition then summarizes conditions under which we obtain a risky regime, with neither a financial accelerator nor a decelerator. Proposition 2: Given Assumption 3, when $\beta$ and $k$ are both sufficiently close to 0 , there exists an equilibrium in which only a risky regime occurs, and the economy responds to shocks as if it were unconstrained.

Finally, we consider parameter values for which there is a safe regime and a risky one, but no default regime. In this case, as discussed above, there will be a financial accelerator for high house prices but a financial decelerator as we move into the risky regime (the risky regime itself will behave as if unconstrained). As above, taking $\beta$ sufficiently low rules out the default regime, since it means that it is no longer worthwhile for the good types to try to separate from the bad types. However, to obtain a safe regime we must now take $k$ to be sufficiently high; intuitively this is needed so that the borrowing in the safe regime (which is increasing in $k$ ) 
exceeds that in the risky regime when house prices are high. In particular, from equation (A-6) we need $k>1 / 2-\beta$ so as to ensure that borrowing cannot be risky for $p_{1 d}$ close to 1 . This is illustrated in Fig. 4 below. As above, in order to ensure that equilibrium exists, we restrict the domain of the demand shocks: ${ }^{16}$

Assumption 4: $\delta_{d} \in\left[\frac{3(1-2 \sigma(1-\beta)}{2(1-\sigma)}, \frac{2-\sigma-2 k \sigma}{1-\sigma}\right]$.

This then gives us the following Proposition.

Proposition 3: Given Assumptions 1 and 4, when $\beta$ is sufficiently close to 0 , but $k>1 / 2-\beta$, there exists an equilibrium in which either a safe regime or a risky regime can occur. There is a financial accelerator in the safe regime, the economy responds to shocks as if it were unconstrained in the risky regime, and there is a financial decelerator in the transition from the safe regime to the risky regime.

\subsection{Empirical Implications}

We now discuss the empirical implications of our model.

First recall that - as discussed in section 4.1 above - a financial accelerator prevails only in the safe regime, i.e. when house prices are high. So in light of Proposition 1, our model predicts that the response of house prices to demand shocks should be greater when house prices are high than when they are low.

We can also derive another, more detailed, empirical implication, namely that recent reforms in U.S. bankruptcy laws should increase the sensitivity of house prices to demand shocks. Some have argued (Mann, 2007 and also White, 2007) that the primary effect of the recent reform of U.S. bankruptcy laws (the Bankruptcy Abuse Prevention and Consumer Protection Act of 2005) is to make default more costly for borrowers (for example by increasing lawyers' fees) while leaving the amount actually collected by creditors

\footnotetext{
${ }^{16}$ This assumption simply combines the relevant bounds from Assumptions 2 and 3.
} 
relatively unchanged. We therefore interpret these reforms as having raised the personal cost of default $k{ }^{17}$

We now show that in our model a higher personal default cost $k$ implies a lower house price for which the transition out of the safe (financial accelerator) regime occurs. To see this, first consider the case in which only the safe and default regimes exist. Then, as discussed in appendix A, the good types always prefer the safe regime when feasible, and thus the transition out of the safe regime occurs at $p_{\text {nodef }} \equiv \frac{1+e^{k}(3-2 k)+2 k}{4 e^{k}}$, which is the lowest price for which the bad types are willing to refrain from defaulting when offered $b_{\text {safe }}$. This is decreasing in $k$, since for higher $k$ defaulting is more costly for the bad types. Similarly, when the risky regime exists as well, then while the exact price for which we shift from the safe to the risky equilibrium must be calculated numerically, we can nevertheless see that this cutoff must be decreasing in $k$. The reason is that the utility ${ }^{18}$ the good types receive in the safe regime, $\log \left[\frac{3+2 k-4 p_{1 d}}{1-2 p_{1 d}}\right]-k$, is increasing in $k$ for the parameter values that we consider, whereas the utility they accrue in the risky regime, given by (A-10), does not depend on $k$.

Thus these reforms imply that we are more likely to be in the safe regime, with its financial accelerator, and less likely to observe a financial decelerator. So our model predicts that, on average, house prices should now be more sensitive to shocks.

\footnotetext{
${ }^{17}$ To be precise, the cost of a bankruptcy filing affects the decision to default on a secured mortgage in two ways. First of all, as discussed above, in states that permit deficiency judgments, homeowners use bankruptcy filings to limit the amount lenders can take from their other assets. In addition, as is well-known (Leonard, 1999) chapter 13 bankruptcy filings are often used by homeowners in distress as a way to slow down the foreclosure process - either to give them time to become current on their payments or else simply to extend the period during which the borrower can remain in his home without making payments. Jacoby (2007) discusses the possible impact of the recent bankruptcy reform on foreclosures.

${ }^{18}$ This expression is obtained by substituting the expression for $b_{\text {safe }}$ into the good types' utility (A-9) in this case.
} 


\section{$5 \quad$ Examples}

In this section we present several examples that illustrate the possible types of equilibria that can occur in our model. We will initially take half the population to be strategic consumers $(\sigma=0.5)$ and assume the default cost for the bad types is $k=0.4$; this gives us the widest possible range of equilibria.

The first case we consider is $\beta=0.4$. Referring to Fig. 2 above and Proposition 1, we can see that these parameters correspond to region S-D, that is, the safe regime for high values of $p_{1 d}$ and the default regime for low values. This combination occurs because (i) with a relatively high value of $k$ $(k=0.4)$ it is not too costly for the good types to restrict their borrowing to the level at which the bad still repay and (ii) with many bad types $(\beta=0.4)$ the risky equilibrium — in which the bad types default — would be very costly for the good types. As discussed in Proposition 1, in this case we have a financial accelerator for high values of the house price, but strategic default then stabilizes the economy for lower prices.

We begin by choosing the per capita spending by the outside sector $\delta_{d}$ so as to calibrate the model at $p_{1 d}=1$. We then lower $\delta_{d}$; the results are plotted in Fig. 3 below. As we do so, the price clearly falls. Observe that the slope is relatively steep; this reflects the financial accelerator in the safe regime.

When we reach $p_{1 d}=p_{\text {nodef }}=0.85,{ }^{19}$ the bad types no longer wish to repay and we switch to the default regime. In the default regime the slope of the price as a function of $\delta$ is less steep — indeed, as discussed above this regime behaves as if it were unconstrained. The reason is that when the bad types default in period 1, their wealth in this period no longer decreases as the house price falls. Although lenders recoup some of their losses in the form of a higher interest rate (paid by the good types, who do not default),

\footnotetext{
${ }^{19} p_{\text {nodef }}$ is the lowest price that is consistent with a safe equilibrium; see Eq. (A-2).
} 
the rest is paid in the top node (where the price is much higher). Thus the net effect on consumption in the bottom node is positive relative to the safe regime - that is, default endogenously serves as a stabilizing force and there is no longer a financial accelerator.

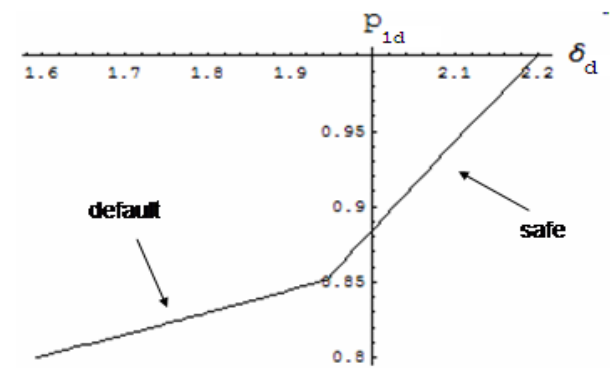

Figure 3: The response of house prices to a change in outside demand $\delta_{d}$ when $\beta=0.4$ (and $k=0.4$ and $\sigma=0.5$ ). The equilibrium shifts from the safe regime to the default regime at $p_{1 d}=0.85$. The safe regime is characterized by a financial accelerator, but strategic default serves as a stabilizing force in the default regime.

Now suppose that $\beta=0.1$. These parameters correspond to the case in which there is no default regime (Fig. 2 and Proposition 3). For high prices we are in the safe regime, with its financial accelerator, and for low prices, we are in the risky regime. Once again default serves as a stabilizing force, although this time it is default in period 2; that is, for low prices the good types find it too costly to restrict their borrowing to the safe level. Observe that there is now a flat region in the transition between the safe and risky regimes - this is a clear example of the financial deceleration that results 
from the bad types' strategic default. We plot the response of $p_{1 d}$ in Fig. 4.

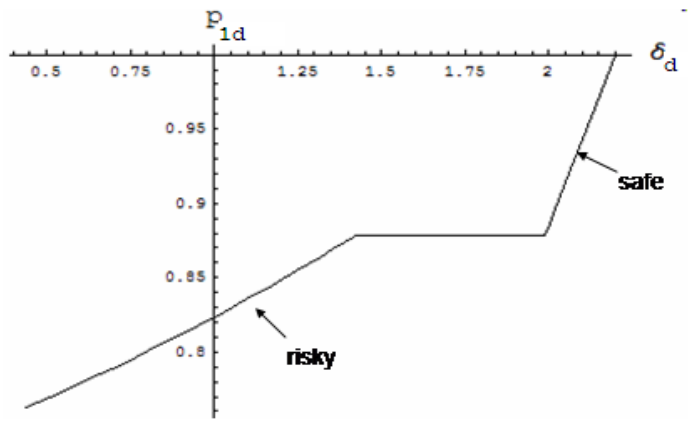

Figure 4: The response of house prices to a change in outside demand $\delta_{d}$ when $\beta=0.1$ (and $k=0.4$ and $\sigma=0.5$ ). Borrowing is such that the risky agents default in period 2 for $p_{1 d} \leq 0.88$. This additional borrowing serves as a stabilizing force in the risky regime, and there is a financial decelerator in the transition from the safe to the risky regime.

Finally, let $\beta=0.15$ and $\sigma=0.1{ }^{20}$ In this case, as we vary the outside demand and hence the market-clearing house price, all of the regimes can occur; this is plotted in Fig. 5. As we move from the safe to the risky regime, the economy behaves just as in the previous example. Notice, however, that there is also a discrete jump down in $p_{1 d}$ when we switch from the risky to the default regime. Finally, recall from the first example that in the default

\footnotetext{
${ }^{20}$ We needed to lower the fraction of strategic agents in this example so that the nonconvexity that occurs when we switch from the risky to the default regime does not force us into the region where the good agents would default as well.
} 
regime demand is higher than in the safe regime and there is no financial accelerator either.

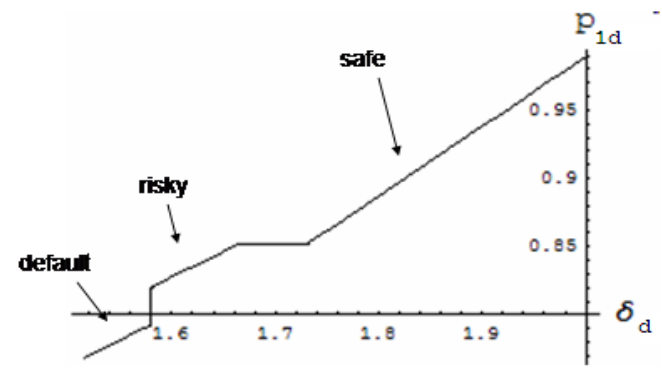

Figure 5: The response of house prices to a change in outside demand $\delta_{d}$ when $\beta=0.15$ (and $k=0.4$ and $\sigma=0.1$ ). The equilibrium shifts from the safe regime to the risky regime at $p_{1 d}=0.85$ and then to the default regime at $p_{1 d}=0.79$.

\section{Conclusion}

In this paper we have developed a model of secured borrowing in which a drop in the value of the underlying collateral can generate strategic default, which in turn can serve to stabilize aggregate fluctuations because it leaves agents with more wealth precisely when the house price is lowest. Strategic default arises in equilibrium because the presence of adverse selection means that default is not always ruled out by binding borrowing constraints.

Our model has the following empirical implications. First, it predicts that the response of house prices to demand shocks should be greater when 
prices are high than when they are low. The model also implies that, by raising the cost to borrowers of defaulting, the recent reform of U.S. bankruptcy laws should make house prices more sensitive to shocks.

There are several directions in which this model could be extended. One interesting avenue would be to endogenize the partially collateralized debt contract agents use to borrow. This paper also simplifies the effect of default on the banking sector - obviously a rash of bank failures induced by a sharp increase in borrower default could have serious consequences. Finally, it would be interesting to interact our stabilizer with a simple model of investment in which home equity serves to secure business loans, as does indeed seem to be increasingly common. Such a model would also generate interesting tradeoffs and might allow our mechanism to engender positive real effects for the economy as a whole.

\section{Appendix A - Derivation of the Equilibrium}

In this appendix we characterize the equilibrium of the lending game.

It is useful to first study the behavior of the bad types when they default in the bottom node of period 1 , since this will affect the decisions of both agents. Now, if the agents default, they are unambiguously identified as bad (since the good types never default) and so the borrowing constraint ensures that they will never be able to borrow so much that they default in period 2 ; they thus face an interest rate of $r_{d}=1$.

Given their quasi-linear preferences, conditional on being in the bottom node of period 1 they would like to borrow $b$ so as to maximize

$$
\log \left[\left(i_{1}+b\right) / p_{1 d}\right]+\left(i_{1}+b\right) \frac{p_{2 d}}{p_{1 d}}-b
$$

subject to their borrowing constraint $b \leq b_{\max }^{\text {def }} \equiv \frac{4 k p_{1 d}+1}{4 p_{1 d}-2}$ (derived in (2) above). Given that $p_{2 d}=1 / 2$ and $i_{1}=1 / 2$, the optimal value is $b=\frac{2 p_{1}+1}{4 p_{1}-2}$. This is never less than the constrained level $b_{\max }^{\text {def }}$ whenever $k \leq 1 / 2$, so the 
borrowing constraint will always bind when the bad types default and they will indeed borrow $b_{\max }^{\text {def }}$.

The resulting utility for these agents will then be

$$
\log \left[\frac{1 / 2+b_{\max }^{\mathrm{def}}}{p_{1 d}}\right]-2 k=\log \left[\frac{1+2 k}{2 p_{1 d}-1}\right]-2 k ;
$$

the term $-2 k$ results from the fact that (i) the agents are defaulting in period 1, and then (ii) borrowing their maximum into period 2 (the maximal borrowing leaves them indifferent to defaulting or not in period 2 , hence the extra $-k)$.

We now turn our attention to the characterization of the equilibrium regimes, which are determined by the borrowing in period 1 and repayment behavior in period 2. Recall that the Wilson-Miyazaki equilibrium must be immune to the introduction of new contracts that attract either the good or bad type; we will first ensure that the bad types do not want to deviate from the candidate equilibrium; we then determine when these regimes are also robust to deviations by the good types.

\section{Safe Regime}

First of all, we may be in a pooling equilibrium - in this case both types repay their initial loan in period 1 . One type of pooling equilibrium is characterized by borrowing that is sufficiently restricted that the bad type also does not default in period 2; we term this the "safe regime" since there will be no default in either period.

From the borrowing constraint given in (1), this would necessitate the borrowing to be no more than $b_{\text {safe }}$, defined by:

$$
\left[1 / 2+2\left(p_{1 d}-1\right)+b_{\text {safe }}\right] \frac{p_{2 d}}{p_{1 d}}-b_{\text {safe }}=-k .
$$

This is determined by noting that (i) the bad type has default cost $k$, (ii) the post-repayment period- 1 wealth of the agents in this pool 
is $1 / 2-2\left(p_{1 d}-1\right)$ and finally, (iii) the interest rate in period 2 is $r_{d}=1$, since there is no default by construction. The solution to this is $b_{\text {safe }}=\frac{4(1+k) p_{1 d}-3}{4 p_{1 d}-2}$, which was already given in (4) above.

The Wilson-Miyazaki equilibrium must in fact be characterized by borrowing up to this maximum. Were this not the case, then a lender could profitably attract both types by offering a slightly larger loan; this would be accepted by both types given their income of $i=1 / 2$ and the second-period house price of $p_{2 d}=1 / 2 .^{21}$

It is important to note that this is an admissible candidate equilibrium only when the bad types do not want to deviate by defaulting. For the bad types to be willing to repay in period 1 , it must be the case that the utility they derive from repaying and pooling with the good types is at least as high as the utility - given in (A-1) above - that they get from defaulting and separating themselves.

That is, the bad types will repay when

$$
\log \left[\left(1 / 2+2\left(p_{1 d}-1\right)+b_{\text {safe }}\right) / p_{1 d}\right]-k \geq \log \left[\frac{1+2 k}{2 p_{1 d}-1}\right]-2 k
$$

i.e.,

$$
\log \left[2+\frac{1-2 k}{1-2 p_{1 d}}\right]-k \geq \log \left[\frac{1+2 k}{2 p_{1 d}-1}\right]-2 k .
$$

Solving this, we can determine that the bad agents are willing to repay when $p_{1 d}$ is above

$$
p_{\text {nodef }} \equiv \frac{1+e^{k}(3-2 k)+2 k}{4 e^{k}}
$$

For the extreme case of $k=0$ we have $p_{\text {nodef }}=1$, which means that the bad agents would never want to repay under these terms (and so this regime would not exist). In general, however, $p_{\text {nodef will be below }}$

\footnotetext{
${ }^{21}$ To see this, note that since the bad types' borrowing constraint binds when they default, it will also bind here (for both types) when they repay and have lower income.
} 
1 , since a higher $k$ both makes default more costly and increases the maximal safe borrowing level.

\section{Risky Regime}

Another type of pooling equilibrium occurs when everyone repays in period 1 , but the borrowing in period 1 is high enough that the bad types default in period 2 .

Given period-1 borrowing $b$, the interest rate $r_{d}$ that is payable in period 2 is now the solution to the following equation:

$$
b=(1-\beta) b r_{d}+\beta\left(1 / 2+2\left(p_{1 d}-1\right)+b\right) \frac{p_{2 d}}{p_{1 d}}
$$

The left-hand side is the amount $b$ that is borrowed; on the right we have the amount repaid. This expression is derived as follows. There is a measure $1-\beta$ of good types, who repay $b \cdot r_{d}$, which is the entire loan plus interest. Conversely the bad types default and repay only their collateral, which is worth $\left(1 / 2+2\left(p_{1 d}-1\right)+b\right) \frac{p_{2 d}}{p_{1 d}}$ in period 2 . It is not hard to derive a closed-form expression for $r_{d}$; in the interests of space it will not be reported.

In order to be a Wilson-Miyazaki equilibrium, the borrowing $b$ must be immune to the introduction of new contracts that attract either the good types or the bad. We begin with the good types.

The good types' utility as a function of their borrowing $b$ is

$$
\log \left[\frac{1 / 2+2\left(p_{1 d}-1\right)+b}{p_{1 d}}\right]+\left[1 / 2+2\left(p_{1 d}-1\right)+b\right] \frac{p_{2 d}}{p_{1 d}}-r_{d} b
$$

and the value of $b$ that maximizes this expression is

$$
b_{\text {risky }}=\frac{14 p_{1 d}-3-4 \beta p_{1 d}-8 p_{1 d}^{2}}{4 p_{1 d}-2} .
$$

There are, however, two constraints that must be satisfied. First, 
$b_{\text {risky }}$ cannot exceed the good types' borrowing constraint $b_{\max }^{\text {nodef }}$, as derived in (3) above. For the parameter values we consider, however, it can be shown that this borrowing constraint never binds for the good types. ${ }^{22}$

In addition, $b_{\text {risky }}$ must also be immune to the introduction of contracts that attract the bad types. In our case, this means that the bad types must (weakly) prefer repaying over defaulting in period 1 . That is, we must have

$$
\log \left[\frac{1+2 k}{2 p_{1 d}-1}\right]-2 k \leq \log \left[\frac{1 / 2+2\left(p_{1 d}-1\right)+b_{\text {risky }}}{p_{1 d}}\right]-k
$$

the left-hand side of this expression is the utility risky agents accrue when they default in period 1 , as calculated in (A-1), while the righthand side is the utility they obtain from repaying and then borrowing

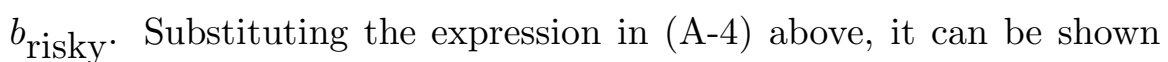
that this occurs if and only if the fraction of bad types $\beta$ satisfies

$$
\beta \leq 1-\frac{1+2 k}{2 e^{k}}
$$

That is, we must have $\beta$ and $k$ sufficiently small for the bad types to be willing to repay. The reason is that with high $k$ the bad types can borrow a lot when they default; similarly, when $\beta$ is high, the adverse selection problem is relatively severe when they repay and so $b_{\text {risky }}$ will be low, which again makes repayment unattractive.

Finally, $b_{\text {risky }}$ will be an admissible candidate allocation only for house prices $p_{1 d}$ that are sufficiently low. The reason is that for this regime

\footnotetext{
${ }^{22}$ The reason is that since the good types have $\kappa=1$, their borrowing constraint only binds when $p_{1 d}<3 / 4$. However, since we focus attention on cases in which default is strategic (i.e., in which the agents can repay should they choose to do so), we must in fact restrict attention to parameter values that lead to risky equilibria with $p_{1 d} \geq 3 / 4$ (see Assumption 2 above).
} 
to exist, by definition borrowing must be risky, that is, it must exceed

the safe level of borrowing $b_{\text {safe }}$ (derived above). When $\beta+k \leq 1 / 2$ this holds for all values of $p_{1 d}<1$ (because when $\beta$ and $k$ are low, the safe borrowing level is low relative to the risky level, as discussed below). More generally, we must have

$$
p_{1 d} \leq \frac{5}{4}-\frac{\beta+k}{2}
$$

for the risky regime to exist.

\section{Default Regime}

Finally, the equilibrium may also be separating; that is, the bad types may default in period 1 while the good repay. In this case we would have $r_{d}=1$ (this time because we are in a separating equilibrium), but now the initial interest rate $r_{0}$ would be above 1 . In particular, the initial interest rate $r_{0}$ that those agents who do not default must pay is determined by the lenders' break-even constraint:

$$
1 / 2 \times r_{0}+1 / 2 \times\left[(1-\beta) r_{0}+\beta p_{1 d}\right]=1
$$

This states that the total expected payment per unit must equal the amount borrowed. The agents all repay in the top node (which occurs with probability $1 / 2$ ). In addition, in the bottom node all of the good types (measure $1-\beta$ ) repay. The bad types (of measure $\beta$ ) default and surrender their collateral, which is worth $p_{1 d}$ per unit. Observe that lenders always break even in expectation in every period (i.e., over the two nodes). If there is default in the bottom node of period 1 , for example, so that the bad types do not repay, this raises the interest rate $r_{0}$, which must be paid by all agents in the top node, and by the good types in the bottom node as well (so it can potentially affect their consumption). 
The solution to this equation is $r_{0}=\frac{2-\beta p_{1 d}}{2-\beta}>1$.

As we have mentioned earlier, since the focus of this paper is on strategic default, we will want to restrict attention to parameter values for which the agents are able to repay; that is, for which $i_{1}+2 p_{1 d} \geq r_{0}$. Given this expression for $r_{0}$, we must restrict attention to parameters that yield $p_{1 d} \geq \frac{6+\beta}{8}$ in equilibrium.

This is an admissible candidate equilibrium only when the bad types do indeed prefer to default. That is, the utility that the bad types receive from defaulting in period 1 - calculated in (A-1) above must exceed what they would receive from repaying and then pooling with the good types. This implies a restriction both on the good types' borrowing (it must not be too high) as well as on the house price $p_{1 d}$ (it must be sufficiently low).

In particular, for default to (weakly) dominate for the bad types, the good types' borrowing must leave the bad types indifferent to defaulting; that is, it must be no more than $b_{\text {def }}$, as defined by

$$
\log \left[\frac{1+2 k}{2 p_{1 d}-1}\right]-2 k=\log \left[\frac{1 / 2+2\left(p_{1 d}-r_{0}\right)+b_{\text {def }}}{p_{1 d}}\right]-k,
$$

where the right-hand side is the utility the bad types would receive from repaying in period 1 and mimicking the good types.

The solution to this equation is given by

$$
b_{\mathrm{def}} \equiv \frac{6+\beta-8 p_{1 d}}{4-2 \beta}+\frac{(1+2 k) p_{1 d}}{e^{k}\left(2 p_{1 d}-1\right)}
$$

it is easy to see that since this is below the good types' optimum, this constraint will in fact bind and the good types will indeed borrow $b_{\text {def }}$ in this case.

As mentioned above, for this to be an admissible candidate equilibrium, house prices must also be low enough that the bad types are 
indeed willing to default. The reason is that the bad types always have another alternative available to them, which is to repay, but then borrow the "safe" level $b_{\text {safe }}$ that was derived in (4) above; they could do this even if lenders are aware of their type. When $p_{1 d}$ is sufficiently high, the bad types' income after repaying would also be fairly high and so $b_{\text {safe }}$ would actually exceed $b_{\text {def }}$. In particular, for the bad types to be willing to default we must have $p_{1 d}$ below

$$
p_{\text {def }} \equiv \frac{6+\beta-4 k+2 \beta k+\frac{(2-\beta)(1+2 k)}{e^{k}}}{8} ;
$$

this is obtained simply by setting $b_{\text {safe }}$ equal to $b_{\text {def }}$ and then solving for $p_{1 d}$.

Intuitively, this cutoff is decreasing in the bad types' default cost $k$ (it is again equal to $p_{1 d}=1$ when $k=0$ ). It is also decreasing in the fraction of bad types $\beta$, because the more bad types there are, the higher the initial interest rate $r_{0}$ and thus the more attractive it is to default. Now, it is not hard to show that $p_{\text {def }}>p_{\text {nodef }}{ }^{23}$ which means that at least one of these regimes will always exist (and so equilibrium will also always exist).

We have presented the candidate regimes. In addition, for fixed parameters $\beta$ and $k$, and house price $p_{1 d}$, we have given conditions under which one or more of these regions will be admissible in the sense that they are immune to deviations by the bad type. However, it must also be impossible for any new contract to attract the good types (while being profitable for lenders after all unprofitable contracts are withdrawn). In other words, the Wilson-Miyazaki equilibrium allocation will be the one associated with the regime that maximizes the good types' utility in the bottom node, subject to no deviation by the bad types. These utilities are given by the following

\footnotetext{
${ }^{23}$ This reflects the non-convexity inherent in this model; when all of the bad types default, the interest rate is higher, which makes repaying less attractive.
} 
expressions:

$$
\begin{array}{ll}
\text { Safe: } & \log \left[\frac{1 / 2+2\left(p_{1 d}-1\right)+b_{\text {safe }}}{p_{1 d}}\right]-k \\
\text { Risky: } & \log \left[\frac{1 / 2+2\left(p_{1 d}-1\right)+b_{\text {risky }}}{p_{1 d}}\right]+\left[1 / 2+2\left(p_{1 d}-1\right)+b_{\text {risky }}\right] \frac{p_{2 d}}{p_{1 d}}-r_{d} b_{\text {risky }} \\
\text { Default: } & \log \left[\frac{1 / 2+2\left(p_{1 d}-r_{0}\right)+b \text { def }}{p_{1 d}}\right]+\left[1 / 2+2\left(p_{1 d}-r_{0}\right)+b_{\text {def }}\right] \frac{p_{2 d}}{p_{1 d}}-b_{\text {def }}
\end{array}
$$

Now, by substituting the expressions for $b_{\text {safe }}$ and $b_{\text {def }}$ into the above, one can determine that the utility (A-9) that the good types accrue in the safe regime always exceeds that received in the default regime (A-11) whenever $p>p_{\text {nodef, }}$, where recall that $p_{\text {nodef }}$, given by (A-2) above, is the lowest price for which the safe regime is immune to deviation by the bad types. This implies that whenever the risky regime does not exist (so that we are in case S-D), the good types prefer the safe regime whenever feasible, and thus the transition from the safe to the default regime occurs precisely at $p_{\text {nodef }}$. More generally, however, the determination of which regime is immune to deviations by the good types while still satisfying the bad types' participation constraints must be made using numerical simulation. As described in section 3.2.2, we carry out these calculations for a selection of parameter values $(\beta, k)$, and report which regimes obtain as we vary the house price in Fig. 2 above.

\section{Appendix B - the Top Node}

In this section we briefly discuss the top node.

From our derivation of the first-period interest rate in the previous section, we can see that it is never more than $r_{0}=\frac{9}{8}$. In order to keep the analysis focused on the bottom node, we will restrict attention to parameters in which it is not optimal for agents to default in the top node, neither in period 1 nor period 2; this will be a pooling equilibrium in which both 
types behave in exactly the same way. For this it is sufficient to assume

that the outside demand $\delta_{u}$ is chosen so as to ensure that $p_{1 u}>\frac{11}{8}$. This will imply that the collateral in period 1 is sufficient to cover the required payment of $2 r_{0}$. In addition, this assumption will also ensure that agents are sufficiently wealthy that they do not want to borrow so much that they default in period 2. Their borrowing can be determined by deriving their first-order conditions for this node.

\section{References}

Aghion, P., Hermalin, B., 1990. Legal restrictions on private contracts can enhance efficiency. J. Law, Econ., Organ. 6, 381-409.

Bacchetta, P., Caminal, R., 2000. Do capital market imperfections exacerbate output fluctuations? Europ. Econ. Rev. 44, 449-468.

Bernanke, B., Gertler, M., 1989. Agency costs, net worth, and business fluctuations. Amer. Econ. Rev. 79, 14-31.

Bolton, P., Rosenthal, S., 2002. Political intervention in debt contracts. J. Polit. Economy 110, 1103-1134.

Capone, C.A., J., Bunce, H., Eggers, F., Reeder, W., 1996. Alternatives to Mortgage Foreclosure: A Report to Congress. U.S. Department of Housing and Urban Development, Washington, D.C.

Clauretie, T. M., Herzog, T., 1990. The effect of state foreclosure laws on loan losses: Evidence from the mortgage insurance industry. J. Money, Credit, Banking 22, 221-233.

Dubey, P., Geanakoplos, J., Shubik, M., 2005. Default and punishment in general equilibrium. Econometrica 73, 1-37.

European Mortgage Federation, 2002. Efficiency of Mortgage Collateral in the European Union. European Mortgage Federation, Brussels, Belgium. 
Fisher, I., 1933. The debt-deflation theory of great depressions. Econometrica $1,337-357$.

Fisher, S., 1983. Indexing and inflation. J. Monet. Econ. 12, 519-542.

Fuerst, T., 1995. Monetary and financial interactions in the business cycle. J. Money, Credit, Banking 27, 1321-1353.

House, C. L., 2006. Adverse selection and the financial accelerator. J. Monet. Econ. 53, 1117-1134.

Jacoby, M. B., 2007. Bankruptcy reform and homeownership risk. Ill. L. Rev. 2007, 323-346.

Kehoe, T. J., Levine, D. K., 1993. Debt-constrained asset markets. Rev. Econ. Stud. 60, 865-888.

Kocherlakota, N., 2000. Creating business cycles through credit constraints. Fed. Reserve Bank Minneapolis Quart. Rev. 24, 2-10.

Leonard, R., 1999. Chapter 13 Bankruptcy, 4th Edition. Nolo Press, Berkeley, CA.

Mann, R. J., 2007. Bankruptcy reform and the sweat box of credit card debt. Ill. L. Rev. 2007, 375-404.

Miyazaki, H., 1977. The rat race and internal labor markets. Bell J. Econ. 8, 394-418.

Ortalo-Magné, F., Rady, S., 2006. Housing market dynamics: On the contribution of income shocks and credit constraints. Rev. Econ. Stud. 73, $459-485$.

Pence, K., 2006. Foreclosing on opportunity: State laws and mortgage credit. Rev. Econ. Statist. 88, 177-182. 
Rothschild, M., Stiglitz, J., 1976. Equilibrium in competitive insurance markets: An essay on the economics of imperfect information. Quart. J. Econ. 90, 630-649.

Stein, J., 1995. Prices and trading volume in the housing market: A model with down-payment effects. Quart. J. Econ. 110, 379-406.

Tobin, J., 1975. Keynesian models of recession and depression. Amer. Econ. Rev. 65, 195-202.

White, M. J., 2007. Abuse or protection? Economics of bankruptcy reform under BAPCPA. Illinois Law Review 2007, 275-304.

Wilson, C., 1977. A model of insurance markets with incomplete information. J. Econ. Theory 16, 167-207. 